eliminated paradoxical movement. Despite the gross backward displacement of the heart the child did not suffer the haemodynamic consequences of cardiac tamponade, probably because this developmental defect was associated with considerable distension of the pericardial sac.

We thank Dr Pickering for permission to report this case, also Dr J Van Jones, and Dr E W Fletcher.

\section{References}

1 Zerella J T, Halpe D C E. Intrapericardial teratomaneonatal cardiorespiratory distress amenable to surgery. J Pediatr Surg 1980; 15: 961-3.

2 Reynolds J L, Donehue J K, Pearce C W. Intrapericardial teratoma-a cause of acute pericardial effusion in infancy. Pediatrics 1969; 43: 71-8.

3 Smith L, Lippert K M. Peritoneo-pericardial diaphragmatic hernia. Ann Surg 1958; 148: 798-804.

4 Gross R E. Congenital hernia of the diaphragm. Am J Dis Child 1946; 71: 579-92.

5 Thomsen G, Vesterdal J, Winkel Smith C C. Diaphragmatic hernia into the pericardium. Acta Paediatrica 1954; 43: 485-92.

6 Einzig S, Munson D P, Singh S, Castaneda-Zuniga W, Amplatz K. Intrapericardial herniation of the liver: uncommon cause of massive pericardial effusion in neonates. AJR 1981; 137: 1075-7.

Correspondence to Dr Janet A Eyre, Neonatal Unit, Department of Paediatrics, John Radcliffe Maternity Hospital, Headington, Oxford OX3 9DU.

Received 7 October 1982

\title{
Serosal miliary Crohn's disease in association with probable coeliac disease
}

\author{
J F T GLASGOW, C R PINKERTON, AND J M SLOAN \\ Department of Child Health and Department of Pathology, The Queen's University of Belfast
}

SUMMARY A 2-year-old boy with peritoneal miliary Crohn's disease is described. In addition to vague gastrointestinal symptoms, ascites was a prominent feature. The jejunal mucosa was markedly atrophic, compatible with a diagnosis of coexistent coeliac disease.

The incidence of Crohn's disease seems to be increasing. It occurs infrequently below school age and is rare before 2 years of age. Although the disease may affect large areas of bowel, in those with atypical manifestations the diagnosis may be reached with difficulty. Recently, a young child with persistent vague gastrointestinal symptoms but obvious ascites was found at laparotomy to have serosal miliary Crohn's disease. Previous cases with this presentation have been aged between 13 and 53 years. $^{1-4}$

\section{Case report}

A 27-month-old boy presented with a 2-week history of loose, watery stools, episodic vomiting, and striking abdominal distension. He was adequately nourished and of average height. A plain radiograph of the abdomen showed colonic dilatation and some air-fluid levels. He was managed conservatively and within 48 hours the symptoms had resolved spontaneously. One week later he developed general malaise, anorexia, constipation, and loss of weight. Abdominal distension was again prominent, but no localised abdominal lesion was palpable. Laboratory studies were unhelpful and he continued to be unwell.

Exploratory laparotomy showed no abnormalities; the appendix was histologically normal, as were some adjacent lymph nodes which contained reactive hyperplasia.

The child remained unwell, was anorexic, and had a persistently distended abdomen. During the next 3 weeks body weight declined from 12.9 to $11.7 \mathrm{~kg}$ and total serum protein from 56 to $46 \mathrm{~g} / \mathrm{l}$. Serum albumin was $27 \mathrm{~g} /$ l, alkaline phosphatase (ALP) $111 \mathrm{U} / 1$, cholesterol $2.6 \mathrm{mmol} / 1(100.39 \mathrm{mg} / 100 \mathrm{ml})$, and iron $2.4 \mu \mathrm{mol} / 1(13.4 \mu \mathrm{g} / 100 \mathrm{ml})$; prothrombin time and blood count were each within normal limits. Peroral jejunal biopsy showed profound villus atrophy, with pronounced crypt hyperplasia, increased intraepithelial lymphocytes, and a heavy mixed inflammatory cell infiltrate, findings compatible with active coeliac disease. He was started on a gluten-free diet which produced an immediate improvement in appetite and weight. The serum proteins increased to $73 \mathrm{~g} / 1$.

His condition soon deteriorated however, and within 6 weeks he was found to have pronounced abdominal distension now accompanied by ascites, 
the protein content of which was $44 \mathrm{~g} / 1$. At a second laparotomy dense adhesions were present as well as multiple discrete creamy miliary lesions, $2-4 \mathrm{~mm}$ in diameter, studded over the surface of nearly the entire small and large gut's serosal surface and on the greater omentum; some of these lesions were confluent and formed 'chains', which were slightly raised giving the appearance of bacterial colonies seeded upon a culture medium. Biopsy of the omentum revealed numerous granulomas (Figure) containing Langhans's giant cells, but no obvious caseation, acid-fast bacteria, doubly-refractile matter, or larval fragments.

Biopsy of a mesenteric lymph node again showed reactive changes, but granulomas were not detected in multiple sections. The liver had a finely nodular surface and biopsy showed mild focal liver cell necrosis and an increase in fibrous tissue with some bridging fibrosis. There were neutrophils within the portal tracts together with a chronic inflammatory cell infiltrate which contained numerous eosinophils. Occasional granulomas were scattered randomly throughout the lobules. Neoplasm was not present.

Postoperatively wound healing was slow with keloid formation. The erythrocyte sedimentation

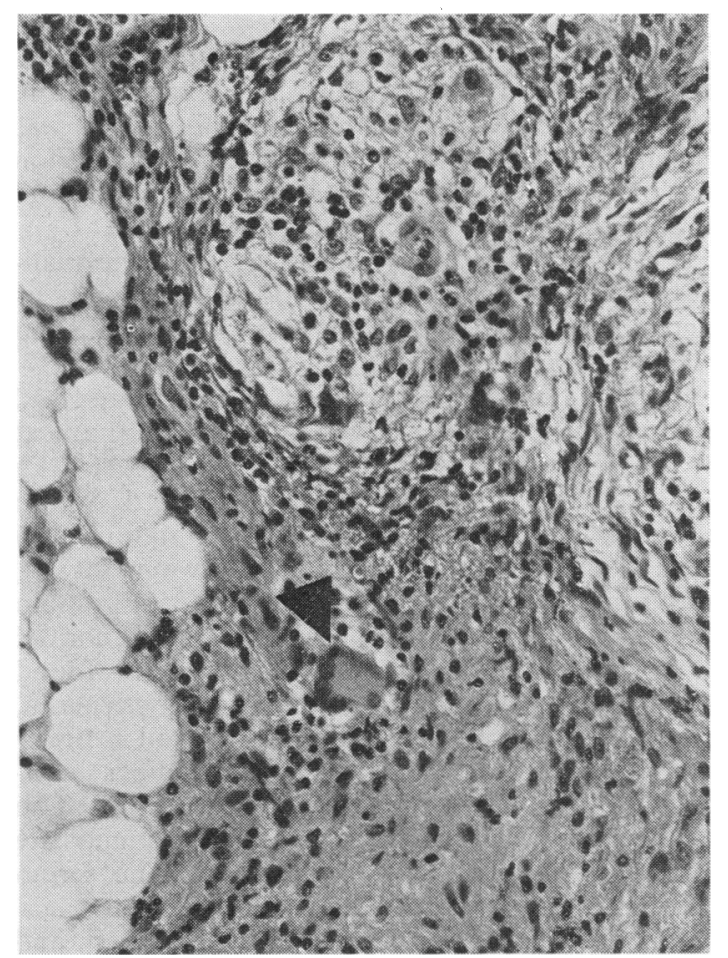

Figure Granulomas with Langhans's giant cells (arrowed) seen within the omental fat. $\times 150$. rate was $4 \mathrm{~mm}$ in the 1 st hour, Mantoux test $(1$ in 100) was negative on two occasions and Mycobacterium tuberculosis could not be identified in or cultured from sputum, gastric washings, or ascitic fluid. A chest radiograph was normal. Simple tests of hepatic dysfunction were AST 18, ALT 9, ALP $133 \mathrm{U} / 1$, total bilirubin $5 \mu \mathrm{mol} / 1$ $(0.29 \mathrm{mg} / 100 \mathrm{ml})$. Peripheral eosinophils were 280 and $350 / \mu 1$ on two occasions. The optic fundi were unremarkable. On barium meal examination the proximal jejunal loops were dilated, sigmoidoscopy was unremarkable, and rectal biopsy was normal. In view of the operative and histological findings the child was considered to have Crohn's disease of the serosal, miliary variety and was started on sulphasalazine $(1.5 \mathrm{~g} /$ day $)$. In the subsequent 3 weeks general health, appetite, and energy improved; bowel motions became regular and over a longer interval abdominal distension gradually diminished. Further episodes of vomiting, altered bowel habit, or abdominal distension have not occurred and in a 2-year interval growth in height (25th centile) and weight (50th centile) remain satisfactory.

\section{Discussion}

The differential diagnosis focused upon the intraabdominal serosal granulomas. In view of the 3month interval since the first abdominal exploration, it seemed possible that the granulomas were caused by foreign material introduced on that occasion (for example talcum powder or starch) which had provoked a foreign-body giant cell reaction. However, the peritoneal granulomas were exceedingly widespread, the multi-nucleated cells were of the Langhans's type (Figure), and granulomas studied under polarised light failed to reveal doublyrefractile bodies. Sarcoidosis was unlikely also, as abdominal disease has not been described even in adults with generalised sarcoidosis. Although less common than formerly, tuberculous peritonitis or enteritis remained possibilities, particularly in the presence of exudative ascites. This was excluded by the negative Mantoux test and bacteriological findings. Lymph node involvement in tuberculosis is virtually a sine quo non, but here detailed study of mesenteric nodes failed to show a single granuloma.

On the contrary, the histology (Figure) was consistent with Crohn's disease. Granulomas were not identified in superficial mucosal biopsies of jejunum or rectum, but such specimens are known to be of limited value even in well-established disease. ${ }^{5}$ The miliary form of Crohn's disease appears to be an initial, transient occurrence and is unrelated to prognosis (K W Heaton, 1981, personal communication). 
The presence in the hepatic granulomas of eosinophils raised the possibility of Toxocara infestation. Larval remnants were not present within the granulomas nor was there peripheral eosinophilia or any other manifestation of larval migration-for example chorioretinitis. Although there are numerous causes of hepatic granulomas the liver in this case showed features previously reported in extensive Crohn's disease ${ }^{6}$-namely pericholangitis, inflammation of the portal tracts, and increased fibrosis.

How should we interpret the presence in our patient of virtual total villus atrophy? Two reports of the coexistance of Crohn's and coeliac diseases are extant ${ }^{78}$; each was associated with other evidence of classical Crohn's disease however, and upon withdrawal of dietary gluten there was clear histological evidence of mucosal recovery. In Crohn's disease per se, a variety of small-bowel mucosal abnormalities has been described. ${ }^{5}$ These are usually of a patchy nature and are most obvious adjacent to areas of frank mucosal ulceration. The case reported by Daum et al. ${ }^{3}$ was found initially to have mucosal changes suggestive of coeliac disease on jejunal biopsy but in comparison with our case, the abnormalities were not severe nor did symptoms remit after gluten withdrawal. Our patient requires further study to confirm persisting gluten sensitivity, nevertheless, it seems improbable that the abnormal jejunal histology is a manifestation of Crohn's disease per se.

\section{References}

1 Heaton K W, McCarthy C F, Horton R E, Cornes J S, Read A E. Miliary Crohn's disease. Gut 1967; 8: 4-7.

2 Manns J J. Miliary Crohn's disease. Br Med J 1972; ii: 152.

3 Daum F, Boley S J, Cohen M L. Miliary Crohn's disease. Gastroenterology 1974; 67: 527-30.

4 Bartnik W, Krynski J, Butruk E, Orlowski J. Miliary Crohn's disease. Br Med J 1977; i: 1135-6.

5 Nugent F W, Richmond M, Park S K. Crohn's disease of the duodenum. Gut 1977; 18: 115-20.

6 Eade M N, Cooke W T, Brooke B N, Thompson H. Liver disease in Crohn's colitis. Ann Intern Med 1971; 74: 518-28.

7 Anonymous. Clinicopathological conference: a case of Crohn's disease in a patient with treated adult coeliac disease. Br Med J 1967; iv: 222-6.

8 Eular A R, Ament M E. Celiac sprue and Crohn's disease: an association causing severe growth retardation. Gastroenterology 1977; 72: 729-31.

Correspondence to Dr J F T Glasgow, Department of Child Health, Institute of Clinical Science, Grosvenor Road, Belfast BT12 6BJ.

Received 27 August 1982

\section{Laryngospasm as a single manifestation of epilepsy}

\section{J AMIR, S ASHKENAZI, T SCHONFELD, R WEITZ, AND M NITZAN}

Department of Paediatrics and Paediatric Neurology Unit, Beilinson Medical Centr, Petah Tiqva, and Tel Aviv University Sackler School of Medicine, Israel

SUMMARY A 6-year-old girl had recurrent dyspnoeic attacks during sleep caused by laryngospasm. An abnormal electroencephalogram and an excellent response to carbamazepine suggests the possibility that the laryngospasm was a manifestation of epilepsy.

Breathing difficulties are not uncommon during seizure activity. In generalised tonic-clonic seizures the face may become cyanotic during the tonic phase if respiration is suspended, and then becomes jerky and stertorous in the clonic phase. On rare occasions, there is retraction of the tongue with respiratory distress. Prolonged apnoeic spells were also observed in association with other manifestations of epilepsy. ${ }^{12}$
A patient who presented with recurrent nocturnal laryngospasms as the only motor phenomenon of a convulsive disorder, is reported here.

\section{Case report}

A 6-year-old girl was referred to the hospital with a 3-week history of dyspnoeic attacks which occurred only during sleep. She was a bright, well-developed child of healthy, unrelated parents. Pregnancy and delivery had been uneventful. Her developmental milestones had been attained at the appropriate ages, and there was no family history of neurological disease.

Physical and neurological examination showed no abnormalities. The results of laboratory studies, including routine haematological, biochemical, and serological profiles were normal-for example 